Saint Louis University School of Law

Scholarship Commons

All Faculty Scholarship

1995

\title{
Managed Care as Regulation: Functional Ethics for a Regulated Environment
}

Sandra H. Johnson

Saint Louis University School of Law

Follow this and additional works at: https://scholarship.law.slu.edu/faculty

Part of the Health Law and Policy Commons

\section{Recommended Citation}

Johnson, Sandra H., Managed Care as Regulation: Functional Ethics for a Regulated Environment (1995). Journal of Law, Medicine and Ethics, Vol. 23, p. 266, 1995.

This Article is brought to you for free and open access by Scholarship Commons. It has been accepted for inclusion in All Faculty Scholarship by an authorized administrator of Scholarship Commons. For more information, please contact erika.cohn@slu.edu, ingah.daviscrawford@slu.edu. 


\title{
Managed Care as Regulation: Functional Ethics for a Regulated Environment
}

\author{
Sandra H. Johnson
}

A nalysis in bioethics has relied primarily on the identification and application of general principles and on the examination of particular paradigmatic cases. ${ }^{1}$ Principalism and casuistry depend on an assumption of generalizability; that is, that learning and insights gained from an understanding of the principles or the case may be effectively applied to other similar situations. For the most part, the particular characteristics of the institutional setting have not played a central role in these approaches. ${ }^{2}$ It would appear, then, that what has been learned in the context of one health care setting is transferable, with some few adjustments, to another.

The institutional context does make both a practical and a substantive difference, however, and shifting ethical analyses from one context to another has sometimes proven difficult. This has been so, for example, in the context of nursing home care. ${ }^{3}$

\section{Bioethics and managed care}

Acute care bioethics has encountered many problems in translation to managed care systems as well. Ethicists have persistently struggled with developing an appropriate ethic for physicians practicing within managed care systems and for managed care itself. The difficulties emerge from many directions. Managed care raises issues of allocation and limitations, for example, which have not been treated as core issues for individual treatment decisions in the past. In fact, issues of ability to pay, rationing, coverage, and reimbursement were generally viewed as irrelevant as a matter of principle to the central task of analyzing what ought to be done in a particular treatment decision. ${ }^{4}$

Journal of Law, Medicine \& Ethics, 23 (1995): 266-72.

(C) 1995 by the American Society of Law, Medicine \& Ethics.
Some of the mismatch between hospital-based bioethics and bioethics as applied in other health care contexts arises from limitations in the general principles. For example, analysis of an ethical issue under the autonomy principle commonly assumes as its starting point a competent individual living relatively independently and then extrapolates from that assumption to other circumstances. That concept has to be adjusted seriously rather than simply at the margins, if it is to be applied to nursing home residents or home health patients who are severely dependent on daily intimate health care assistance from professionals, aides, and family. ${ }^{5}$

The scope and meaning of the autonomy principle is also fundamentally at issue in coverage decisions in managed care and other health insurance plans. To the extent that managed care is viewed as limiting consumption of at least marginally beneficial health care services, some have claimed that the autonomy principle exercised in the consumer's choice of health plans justifies treatment limitations exercised by those plans. ${ }^{6}$

\section{Bioethics and the organizational context:} managed care as a regulatory environment

Dissonance may also arise from radical differences in the nature and structure of the health care organization. An institutional factor, which may have an impact on ethical decision making and behavior, is whether the dominant decision makers are those engaged solely in patient care or in administrative or management functions. This is not to say that administrators are ethically inferior to caregiving professionals; rather, the administrator-including the physician- or nurse-administrator-clearly has dual roles, including fiduciary duties to the organization and obligations for the well being of patients. The health care admini- 
strator's duty to the institution, the administrator's job description, and the administrator's legal obligations include responsibility for the financial health and growth. of the institution. ${ }^{7}$ In the best of worlds, these duties to the institution are quite compatible with a fiduciary duty to the patient; but, in many situations, they conflict or at least require modification and prioritization. ${ }^{8}$ Both in nursing homes and managed care, management and administration have a very significant role in treatment decisions and thus in ethical issues. The dual roles of the administrator carry an ethical dimension of their own.

Finally, managed care brings its own "institutional" framework to the decision-making process. Managed care is a catch-all phrase for a broad variety of activities and organizations. Core to its definition and key to its distinction from indemnity health plans is that managed care is structured to integrate the insurance risk and the direct provision of care. Managed care uses a very large and developing repertoire of tools to influence individual treatment decisions aggregated over a population, including distributing information to providers on relative effectiveness and cost of treatment; providing financial incentives and disincentives based on risk sharing in the cost of treatment decisions; pre-treatment certification; post-treatment review; practice profiles; practice guidelines; and so forth.

Managed care, like nursing home care, is often characterized by the direct care providers as a highly regulated environment for health care decision making. The regulatory and bureaucratic context in managed care is not public, governmental regulation; rather, it is a private regulatory, bureaucratic environment. There are very important differences between public regulation and private "regulation." For example, value choices incorporated within the standards of a governmental regulatory system may represent a level of societal consensus or political compromise. Functionally, too, significant differences can arise in terms of the location of control in the system, the legal rights of patients and providers, and the procedures for establishing or changing rules.

As a practical matter, however, individual health care professionals often do not distinguish among government regulation, private accreditation standards, risk management policies, payment/reimbursement decisions, or internal corporate rules and policies when they speak of "regulation" that restricts their practice. ${ }^{9}$ From a treating physician's perspective, managed care is often viewed as exerting external control over individual treatment decisions. ${ }^{10}$ The influence is seen as external to the physician-patient dyad, which has been the focus of bioethics and medical ethics during the past generation; and it is seen as controlling even when both the typical managed care contract provides and the legal principle holds that the doctor cannot disclaim responsibility for treatment decisions.

Even though contract terms stating that the physician remains responsible for individual treatment decisions are common, managed care does not defer to physician authority to the degree that the traditional physician-patientindemnity insurer relationship does. In fact, what managed care brings to health care is the goal and ability to intervene in physician-patient decision making through various tools. Intervention may be procedural (requiring the physician to seek approval but always granting approval), nondirective (offering advisory guidelines or aggregate financial incentives), or informational (providing the physician and insurer with individual practice profiles). But whether the tool is merely procedural, completely nondirective, or simply informational, the formal and informal penalties to providers for violating or testing the boundaries of the "rules" implicit in these tools are tangible in terms of financial or other material costs of time, administrative resources, and human energy.

Finally, in managed care, as in nursing home care, the influence or control that is pilloried as an obstacle to good care responds to known quality problems in the system. For nursing homes, the restrictive environment responds to the history of negligent care and the particular vulnerability and isolation of the resident population. ${ }^{11}$ For managed care, the restrictive environment responds to incentives to overtreatment in the traditional fee-for-service (FFS), physician-driven indemnity structure. ${ }^{12}$ Managed care also reacts to the former insurance-provider alliance in which provider and insurer interests sometimes combined to provide excessive and nonproductive treatment in a price-insensitive system. ${ }^{13}$ So the regulations for each of these restrictive environments capture some notion of the good, even as they create challenges to ethical decision making.

A core question for managed care is what specific level of medical treatment should doctors provide to individual patients and should patients expect under this framework. The discussion that follows aims to mark a path to that question by clearing out some of the underbrush that providers, patients, and managed care organization (MCOs) encounter-or create-before that definitive issue can be or should be confronted.

\section{"They made me do it"}

Significant anecdotal evidence suggests that doctors perceive managed care regulations as preventing them from behaving in an ethical manner, or at least from doing what they believe is best for their patients in certain circumstances. The current controversy over the appropriate length of stay for childbirth provides an example.

Several states have recently passed or considered legislation mandating coverage of minimum postpartum hospital stays in response to the guidelines accepted by the American College of Obstetricians and Gynecologists (ACOG) and the American Academy of Pediatrics (AAP). 
The legislation and ACOG and AAP guidelines respond both to data indicating an overall reduction in length of stay after delivery and to complaints concerning payer restrictions on coverage of postpartum hospitalization. One obstetrician said that she was visited by a representative of an insurer who presented her practice profile in chart form. The insurer said she would remain in the system because of her low rate of Caesarian sections, but she needed to get her patients out of the hospital faster. This doctor stated that she viewed that conversation as a message to discharge her patients more quickly or to face termination from the plan. ${ }^{14}$ The chief executive officer of the Minnesota Medical Association stated that while insurance companies say it is the doctor's decision, the doctors "have to jump through a lot of hoops to [keep their patients hospitalized beyond the minimum]." ${ }^{15}$ Another physician reported that her patients were billed for part or all of the hospital's charges for hospital stays that exceeded the twenty-four-hour "guidelines."

On the other hand, many insurers report that they do not maintain short-stay requirements: one insurer stated that the twenty-four-hour standard "was never meant as a strict twenty-four-hour policy, but ... the provider community has interpreted it as rigid." Because of that interpretation, the insurer was considering altering its policy. ${ }^{17}$ Analysis of the empirical research concerning the benefit or harm of longer or shorter hospitalization is required to evaluate fully the merits of the dispute. But what is interesting for purposes of this article is the interaction between individual physicians and MCOs concerning postpartum hospitalization rules.

\section{Whose rules?}

The complaint, that the regulations at times restrict good care, may be pointing the finger at the wrong target. The managed care insurer or reviewer may be blamed, for example, when the culprit is the rules and policies established by another entity, such as a hospital responding to a managed care environment.

Clearly identifying the source of the prohibition or constraint is critical for effective analysis of the problem. The question of whether the MCO and the insured have contracted for a particular service or intervention, for example, should be treated differently than the question of whether the hospital's efforts to be generally fiscally attractive to the payer market should influence the level and style of treatment available to that patient. Managed care plans are not uniform; some cover specific services and treatments that others do not, and some establish a pattern of denials or approvals that differs from others in like cases. Some patients have actually paid for coverage that is less restrictive than what other consumers have chosen. Moreover, while managed care may dominate some regional markets, that domination is not complete, and some patients have purchased FFS physician-driven coverage. Institutional or facility policies that adopt the lowest common denominator among managed care methodologies for all patients could operate to deprive some consumers of the health care benefits or the health care decision-making process for which they have paid.

Even if the physician or other provider has accurately "named the source of the rule or policy that is controlling, other self-interested behaviors may be occurring. These behaviors on the part of the provider and the managed care plan have ethical implications, which are analyzed in the sections that follow.

\section{Scapegoating the regulations}

A threshold question is whether the charge that the managed care plan prohibits good care is asserted honestly. In some cases, the insurance rule may be used as a scapegoat for the provider's own interests. Physician's medical treatment decisions are induced by a number of external factors unrelated to managed care. ${ }^{18}$ The provider might be protecting his or her own financial interests or might be trying to avoid administrative conflict. A physician may find it easier to tell a patient that the insurance company will not "allow" another day in the hospital or an intravenous rather than intramuscular injection of pain medication than to explain that the hospital is monitoring physician practice patterns for resource utilization or that the physician's practice group benefits financially if the patient is discharged sooner or if a less costly but less effective form of pain management is used.

Blaming the insurer's regulations is a particularly powerful source of control because it diverts attention from the real decision maker and from the true reason for the denial. It does so in a fashion that creates an assumption of powerlessness, because the decision appears to be outside the control of the patient or the doctor.

The ethical duty here is quite clear. If the provider gives a reason for the particular decision, he or she has an unequivocal duty to be truthful in presenting those reasons. While some have argued over what the physician must disclose to the patient concerning financial interests, no substantial conflict has arisen over whether the provider must be truthful in the information actually given to the patient. Scapegoating managed care is unethical as a violation of this very limited duty of truthtelling.

Similarly, because the duty of truthtelling is so clearly established, the obverse is also true. Disguising a denial of treatment by the insurer in the clothes of a recommendation based on the physician's professional judgment and ordinary practice also violates this basic principle. Contract provisions that prohibit providers from revealing the plan's denial of approval as the source for the refusal to go 
forward with a particular treatment are inconsistent with the fiduciary duty of honesty to the patient. ${ }^{19}$

Managed care has financial incentives for erecting barriers between insureds and the coverage determination process. But, if the patient does not know that a choice is to be made and does not know who controls or participates in that choice, that patient is less able to complain and pursue claims for treatment against the insurer. If the doctor learns the rules, he or she may be able to "game" them in order to increase the approval rate on his or her claims for pretreatment certification. Providing accurate information can produce financial benefits in terms of risk management, however. Accurate and accessible information allows for correcting misunderstandings and for avoiding breach of standards of care prior to inflicting injury.

Beyond the financial costs and benefits of providing accurate and detailed coverage information, any contractual approach to treatment limitations requires that unconscionable inequities in information concerning the terms of that contract be corrected. The MCO must provide access to accurate and detailed information about coverage if patients are to have any chance of effectively asserting their own interests.

\section{I heard it through the grapevine}

The written rule or regulation simply may not support the provider's claim that the insurer will not pay for the desired intervention. Yet, the provider's understanding of the insurer's rule is honestly asserted. It is possible that the provider is dealing with rules that are different from those written in the benefits documents or in the external communications of the insurer.

Individuals dealing with an extensive body of rules that govern their actions on a daily basis may rely substantially on informal or word-of-mouth sources for the content of the rules. At some point, the time and expense involved in chëcking written standards, making the telephone call to ask specific questions, or asking for pre-treatment certification motivate the provider to seek other sources of information. It is likely that anecdotal information will be available from colleagues or clerical staff as to their past experiences in seeking approvals on behalf of patients. It is simpler to generalize from and to rely on the provider's own or colleagues' past experience. The individual case, however, may be different in a way that would be significant to the payer's decision; or the plan's informal policies, guidelines, or screens for review may have changed; or the previous encounter may have been for a similar treatment but under a different insurance plan.

Any rule-bound system that does not distribute its written rules in an accessible form promotes excessive reliance on informal and perhaps unreliable sources. A system whose rules are inaccessible to those governed by them, such as informal guidelines, training manuals, and strictly internal memoranda, for the application of rules to particular situations will experience a similar behavior. When the rule is unclear, it will have an impact quite different from that intended, to the disadvantage of the patient, the doctor, and, possibly, the insurer.

Another significant component in this problem is the role of the individual case reviewer. Discretion is an inevitable part of any system that requires the application of standards to particular circumstances, as do the retrospective and pre-treatment approval mechanisms of managed care. An ethical system of regulation, however, does not foster uneven application of the rules either intentionally or through neglect. Inconsistency in implementation can occur in several instances.

Systems that rely on case-by-case review should actively monitor the outcomes of this individualized review to assure that irrelevant factors (such as the identity of the doctor, legal representation, race, or gender) do not influence the result. ${ }^{20}$ Responses to treatment inquiries that appear frequently and in recognizable patterns may need greater standardization in order to avoid rationing through procedural obstacles. Furthermore, any system that relies on a pattern of denials at the first level and approvals only after objections are raised or appeals are pursued (and only to the class of individuals who do so) is inequitable and dishonest.

Providers cannot be held to ignore completely the information available on the grapevine. To the extent possible, however, the provider should be held to check the accuracy of such information. The duty of inquiry described here does not necessarily include a duty to contest the actual standards of the MCO, once they are accurately determined. ${ }^{21}$ This duty calls the provider merely to ascertain what the standard of the individual patient's plan is. A duty to advocate on behalf of the patient has generated some controversy, to the extent that it can be viewed as requiring the physician to work against legitimate costeffectiveness standards. ${ }^{22} \mathrm{~A}$ duty of inquiry, in contrast, is necessary in order for the cost-access trade-off to function effectively in the first place.

The MCO should create a "safe place" for inquiries. Contract provisions with substantial penalties for excessive denials of requests for approval are incompatible with this duty of inquiry on the part of individual physicians. Contract penalties for excessive denials create incentives for providers to work well within the plans' own established boundaries, creating a margin of safety for themselves, with the result that patients do not receive medical services for which they have contracted. Medical treatment is rationed according to the timidity of the physician facing "decapitation" or lesser penalty. This is not to say, however, that current legislative efforts to respond to such contracts are workable. ${ }^{23}$ 


\section{All's not well that ends well}

Formal and informal penalties exist in any bureaucratic system. The regulatory context for the very high incidence of physically restrained patients in nursing homes, which existed until the early 1990 s, is one illustration..$^{24}$ No government regulation required that facilities physically restrain large percentages of ambulatory patients to prevent them from falling. But falls and unsupervised departures from the facility required, at a minimum, internal incident reports and usually triggered government investigation. Physically restraining a resident to a bed or chair did not trigger either of these administrative hassles. The cost of a fall thus included the financial and other costs of scrutiny, including completing paperwork, participating in the investigation, responding to the charges, and contesting any penalty. Even though the facility's care might ultimately be accepted as meeting the regulatory requirement or standard of care, the process itself exacted a price for that result. Tying a patient to a bed or chair did not require that an incident report be filed nor would it cause any serious inquiry from the government agency. Simply doing the bad thing-restraining the resident-became the course that was not penalized by the system. Such a state of affairs communicated an unmistakable message: What did the government regulations require? They required restraints. It hardly mattered that no government regulation could be found to support that commonly held belief.

The ideal for health care professionals is to make the "right" care decision despite the costs. But the regulatory system-including administrative systems established by $\mathrm{MCO}$ - in the interest of fairness and effectiveness must also respond. The first step in a regulatory response to the sub rosa penalties of the process is to inventory those penalties.

Contract penalties for specific behaviors or practice patterns may ultimately never be enforced by the plan against the particular provider. Peculiar circumstances or an unusual population mix, for example, may be found on further review to justify the number of submissions for payment or the practice patterns of a particular physician. But the stakes of the penalty and the cost of responding to review of the particular circumstances will necessarily encourage providers to steer clear of the disputed boundary questions, denying treatment that is covered and that the MCO has a duty to provide.

Patterns of first-level denials followed by approvals on more persistent inquiries ${ }^{25}$ or substantial procedural requirements for approvals that are routinely granted create similar problems. A pattern of initial denial and subsequent approval will discourage medical loss (HMO jargon for the amount actually paid for medical services) and can be strategically used to control medical costs. However, such administrative behavior leads to significant quality and equity problems with serious implications for contract and consent theories for allocations made through managed care.

In an inventory of the $s u b$ rosa penalties of the process, financial compensation systems cannot be dissociated from their impact on individual treatment decisions. Although incentive systems generally apply only to the aggregate rather than to individual cases, claims, by the MCO that establishes the system, that it bears no responsibility for their influence in particular cases can only be seen as disingenuous. Although the individual doctor cannot and should not be able to claim the incentive system as a defense for substandard care, the MCO cannot completely dissociate itself from the ethical ramifications of the systems from which it benefits.

\section{The rules are wrong}

While the previous four categories of claims that managed care systems limit good care apply to the way the rules are used strategically by health care providers or by MCOs, this category addresses the standards of care themselves. It does happen that the physician and the patient are right and the plan wrong about whether or not a standard is appropriate and beneficial. Emerging technologies, techniques, and pharmaceuticals require constant reassessment, and the plan's assessment of effectiveness can be out-ofdate or empirically insupportable. But beyond such advances, allocation or cost-effectiveness assessments rest on value judgments that also require reevaluation. The value judgments are most difficult, because they may require striking a balance among competing goods.

The transition from a standard that accepted the use of restraints in nursing homes to a standard that generally views physical restraints as inappropriate and substandard illustrates the combination of ongoing empirical research and values clarification that must occur in standard setting. In the case of physical restraints, the frequent use of restraints reflected a balance of values between autonomy/ freedom and beneficence to vulnerable individuals that favored protection. This weighting was later rejected when claims for increased risk taking, mobility, and autonomy in nursing homes became stronger. The transition in the use of restraints was, in part, a transition in values. Furthermore, when empirical research on the effectiveness of restraints was finally completed, it indicated that the perceived trade-offs between the risks of injuries suffered in falls and the effectiveness of restraints in preventing these injuries had been false. In fact, restraints caused serious iatrogenic injuries and did not necessarily prevent falls. ${ }^{26}$ Cost is a primary concern in nursing home care, and strong assertions that restraints were the only cost-effective means of reducing injury were undermined only when a number of facilities began to report that untying the elderly patients did not cost more and, in fact, might cost less. ${ }^{27}$ 
Situations analogous to that of restraints arise in managed care. Policies established by MCOs for coverage of effective pain relief illustrate how standard setting responds both to scientific and medical advances and to evolving ethical norms. ${ }^{28}$

The administrative response to the problem of "bad" rules might occur on two levels. The first is to accept that the regulations do not always capture, once and for all, the measure of quality care. Sponsored research can contribute an empirical foundation essential for establishing and applying standards to treatment decisions in managed care.

Just as important, setting the standards also requires unpacking decisions to identify the ethical issues embedded in what appear to be wholly scientific or financial questions relating to medical treatment. This is at the core of both quality control regulation and bioethics. Decisions regarding life-sustaining treatment or human experimentation, for example, were transformed from an entirely medical issue to one of choice by isolating the medical issues from the values implicated in those decisions. The range of individuals entitled to participate in the process of evaluating treatment and experimentation expanded once it was recognized that the choice implicated values. ${ }^{29}$ In these traditional bioethics decisions, it has been recognized, though not without controversy, that decision making must incorporate other disciplines and other viewpoints. Widening the table to include physician-contractors in the discussion of coverage and treatment standards in managed care does not reach wide enough. ${ }^{30}$

A distinguishing feature of government standard setting for nursing home regulation has been that cost has always been treated as relevant. The ideal has succumbed to the next best or to minimum standards in the reality of resource limitations. In the context of public regulation, one would recommend a commission or a task force or a negotiated rulemaking process to deal with these types of issues. It is time to look for similar instruments that can be incorporated within MCOs.

\section{Conclusion}

Intensive regulation, both real and perceived or governmental and corporate, contributes to the exaggerated sense of regulatory determinism experienced in nursing homes. The private regulatory and bureaucratic system through which managed care plans influence medical treatment decisions could produce a similar dynamic. But interpreting every claim that the regulations require bad care as an accurate charge against the government regulation and surveillance of nursing homes is misplaced.

Similarly, claims that MCOs require bad care have to be examined under ethical norms. In some cases, managed care is scapegoated. In more than a few cases, the regulation in question is the internal procedure of the health care facility itself, which has been adopted in the facility's own interest. In others, the claim that the regulations prohibit good and compassionate care is based on honest misunderstanding. Sometimes, the failure to provide adequate care is attributable to incentives and disincentives built into the administration of the system rather than to the rules prohibiting particular treatment interventions. Health care providers and managed care plans can respond to these situations more effectively. And, in some cases, the standards are wrong, either as a matter of empirical evidence or as a matter of the value choices inherent in the standards.

The focus in the literature on the ethical challenges confronting physicians and other health care professionals in managed care is well placed. But, for the regulator, setting the standards for treatment coverage and the designing procedural mechanisms for implementing standards of coverage are not value-neutral activities. If these standards are correctly identified as value-based, the process for establishing such standards must broaden.

\section{References}

1. See generally Edmund D. Pellegrino, "The Metamorphosis of Medical Ethics: A 30-Year Retrospective, JAMA, 269 (1993): 1158-62; Karen Rothenberg, "New Perspectives for Teaching and Scholarship: The Role of Gender in Law and Health Care," Maryland Law Review, 54 (1995): 473-87; and Susan M. Wolf, "Shifting Paradigms in Bioethics and Health Law: The Rise of a New Pragmatism," American Journal of Law \& Medicine, XX (1994): 395-415.

2. Conroy is an exception to the norm, in the sense that the court established procedures specifically for the nursing home setting; however, the substantive principles developed in the case did not depend on the setting of care. See In re Conroy, 98 N.J. 321, 486 A.2d 1209 (N.J. 1985).

3. Bart Collopy, Philip Boyle, and Bruce Jennings, "New Directions in Nursing Home Ethics," Hastings Center Report, 21, no. 2 (1991): S1-15. See also Bart Collopy, Nancy Dubler, and Connie Zuckerman, "The Ethics of Home Care: Autonomy and Accommodation," Hastings Center Report, 20, no. 2 (1990): S1-16.

4. Again, some exceptions exist. For example, Judge Blackmar, dissenting in Cruzan, stated:

The absolutist position [to continue treatment that extends life] is also infirm because the state does not stand prepared to finance the preservation of life, without regard to the cost, in very many cases. An absolutist would undoubtedly be offended by an inquiry as to whether the state, by prolonging Nancy's life at its own expense, is disabling itself from extending needed treatment to others who do not have such dire prospects.

See Cruzan by Cruzan v. Harmon, 760 S.W.2d 408, 429 (Mo. 1988).

5. Bart Collopy, "Autonomy in Long Term Care: Some Crucial Distinctions," The Gerontologist, 28 (1988): 10-17.

6. See, for example, Mark A. Hall, "Rationing Health Care at the Bedside," New York University Law Review, 69 (1994): at $740-44$.

7. See, for example, Seth B. Goldsmith, Long-Term Care Administration Handbook (Gaithersburg: Aspen, 1993): at 12430. Some administrators have described compliance with gov- 
Volume 23:3, Fall 1995

ernment regulations to be "at the core of the administrative function." See B. Abramovice, Long Term Care Administration (New York: Haworth Press, 1988): at 173.

8. A growing literature is focusing on the tension inherent in the health care administrator's role, especially when that role is assumed by physicians. See, for example, William L. Kissick, "Bridging the Cultural Gaps," Physician Executive, 21 (1995): 3-6; and David A. Kindig and Anthony R. Kovner, eds., The Role of the Physician Executive (Ann Arbor: Health Administration Press, 1992).

9. See, for example, Daniel McGlinn et al., "A Day in the Life of a Physician," Michigan Bar Journal, 73 (1994): 142-46.

10. See inter alia Barbara J. Linney, "Changes in the Practice of Medicine," Physician Executive, 19 (1993): 59-63; and Virendra Saxena, "Putting Out the Flames that Threaten Medicine," American Medical News, Mar. 22, 1993, at 31. As to nursing home regulations, see, for example, James F. Childress, "If You Let Them, They'd Stay in Bed All Morning: The Tyranny of Regulation in Nursing Home Life," in Rosalie Kane and Arthur Caplan, eds., Everyday Ethics: Resolving Dilemmas in Nursing Home Life (New York: Springer, 1990): 79-89.

11. See, for example, Timothy S. Jost, "Enforcement of Quality Nursing Home Care in the Legal System," Law, Medicine $\&$ Health Care, 13 (1985): 160-72; and Institute of Medicine, Committee on Nursing Home Regulation, Improving the Quality of Care in Nursing Homes (Washington, D.C.: National Academy Press, 1986).

12. On the subject of incentives for overtreatment in feefor-service (FFS) medicine, see Office of Technology Assessment, Defensive Medicine or Medical Malpractice (Washington, D.C.: OTA, OTA 22-23, 104-105, July 1994) (concluding that it was impossible to separate the overtreatment inducements of the medical malpractice system from those of FFS payments).

13. Thomas Bodenheimer and Kevin Grumbach, "The Reconfiguration of U.S. Medicine," JAMA, 274 (1995): 85-90 (using this phrase to describe the Blue Cross/Blue Shield structure prior to the cost-control drive).

14. Holly Roberts, M.D., as described in Jan Ziegler, "DriveThrough Delivery: Bargain or Blunder?," Business and Health, Sept. (1995): at 19.

15. Paul Sanders, M.D., as quoted in Patricia Lopez Baden, "Are Short Stays OK After Births?," Minneapolis Star-Tribune, Aug. 8, 1995, at $1 \mathrm{~A}$.

16. Marina Pisano, "Drive-Through Deliveries," San Antonio Express-News, Sept. 17, 1995, as cited 1995 WL 9502145.

17. David Strand as quoted in Baden, supra note 15, at $1 \mathrm{~A}$.

18. See, for example, Bruce J. Hillman et al., "Physician's Utilization and Charges for Outpatient Diagnostic Imaging in a Medicare Population," JAMA, 268 (1992): 2050-54; and Jean M. Mitchell and Elton Scott, "Physician Ownership of Physical Therapy Services: Effects on Charges, Utilization, Profits and Service Characteristics," JAMA, 268 (1992): 2055-59. Each report on increased utilization where there is self-referral.

19. See, for example, Marc A. Rodwin, "Conflicts in Managed Care," N. Engl. J. Med., 332 (1995): 604-07 (describing such clauses).

20. For an analysis of the impact of race in managed care, see Vernellia R. Randall, "Racist Health Care: Reforming an Unjust Health Care System to Meet the Needs of African-Americans," Health Matrix, 3 (1993): 127-94. There may also be an adverse discriminatory impact on physicians serving poor and minority populations. See Note, "The Impact of Managed Care on Doctors Who Serve Poor and Minority Patients," Harvard Law Review, 108 (1995): 1625-42.

21. Many significant efforts have been made to guide physi- cians on that difficult question. See, for example, Council on Ethical and Judicial Affairs, American Medical Association, "Ethical Issues in Managed Care," JAMA, 273 (1995): 1937-42; Susan M. Wolf, "Health Care Reform and the Future of Physician Ethics," Hastings Center Report, 24, no. 2 (1994): 28-41; and Ezekiel J. Emanuel and Nancy N. Dubler, "Preserving the Physician-Patient Relationship in the Era of Managed Care," JAMA, 273 (1995): 323-29.

22. Of course, the physician and the MCO have a legal duty to provide the patient with treatment required under the applicable standard of care. For a complete discussion of the relative legal liability of doctors and managed care, see Barry R. Furrow et al., Health Law (Minneapolis: West Treatise Series, 1995): ch. 8 .

23. California has enacted a statute to protect physicians from termination in retaliation for acting as an "advocate for appropriate health care for their patients." See Cal. Bus. \& Prof. Code $\$ 2056$. This statute was based on legislation developed by the American Medical Association. Similar legislation was passed by the Texas legislature, but was vetoed by the governor. See PR Newswire, "Statement of the Group Health Association of America on Veto of Texas Physician Protection Legislation," June 18, 1995.

24. For background on the regulatory and other legal issues regarding physical restraints, see Marshall B. Kapp, "Nursing Home Restraints and Legal Liability: Merging the Standard of Care and Industry Practice," Journal of Legal Medicine, 13 (1992): 1-32; and Sandra H. Johnson, "The Fear of Liability and the Use of Restraints in Nursing Homes," Law, Medicine of Health Care, 18 (1990): 263-73.

25. For a review of such a situation in another context, see Duggan v. Bowen, 691 F. Supp. 1487 (D.D.C. 1988). In this case, the court reviewed an agency action in which the definition of "part-time or intermittent" home health care was altered, through a transmittal letter to intermediaries, to exclude part-time care if given over more than five days per week. The Department of Health and Human Services routinely denied coverage for more extensive home care services, but routinely granted coverage on appeal to its highest level of appeal.

26. L. Evans and N. Strumpf, "Tying Down the Elderly: A Review of the Literature on Physical Restraint," Journal of the American Geriatric Society, 37 (1989): 65-74; and Arthur H. Dube and Erik K. Mitchell, "Accidental Strangulation from Vest Restraints," JAMA, 256 (1986): 2725-76.

27. See, for example, Letter from Vivienne Wisdom, Executive Director of the New Hampshire Health Care Association to John Sununu, Mar. 11, 1991 (describing that the members of the New Hampshire Health Care Association (a nursing home trade association) experienced "profound improvement in the quality of life," increased staff morale, and more frequent visitors to residents on reduction of restraints).

28. See, for example, Council on Ethical and Judicial Affairs, supra note 21 (describing a choice between contrast media based on cost and pain); and Edmund Faltermayer, "Will the Cost of Cutting in Health Care Kill You?," Fortune, 130 (1994): 221-27 (describing how less invasive techniques preferred in managed care can avoid painful outcomes for patients).

29. See, for example, David Rothman, Strangers at the Bedside: A History of How Law and Bioethics Transformed Medical Decision Making (New York: Basic Books, 1991).

30. See, for example, Janice Somerville, "Doctors, HMOs Give Peace a Chance: Colorado Providers Negotiate Pact on Physician Contract Protections," American Medical News, Apr. 3,1995 , at 3 . 
Copyright of Journal of Law, Medicine \& Ethics is the property of Blackwell Publishing Limited and its content may not be copied or emailed to multiple sites or posted to a listserv without the copyright holder's express written permission. However, users may print, download, or email articles for individual use. 